\section{(6) OPEN ACCESS}

\title{
Development of a robust protocol for gene expression analysis using formalin-fixed, paraffin-embedded liver transplant biopsy specimens
}

\author{
Emily Thompson, Alastair D Burt, Catriona E Barker, John A Kirby, John G Brain
}

Applied Immunobiology and Transplantation Research Group, Faculty of Medical Sciences, Institute of Cellular Medicine, Medical School,

Newcastle University, Newcastle upon Tyne, Tyne and Wear, UK Correspondence to Professor John A Kirby, Applied Immunobiology and Transplantation Research Group, Faculty of Medical Sciences, Institute of Cellular Medicine, Medical School, Newcastle University, Newcastle upon Tyne, Tyne and Wear NE2 4HH, UK; john.kirby@ncl.ac.uk

Received 15 February 2013 Revised 2 April 2013 Accepted 9 May 2013 Published Online First 11 June 2013

\begin{abstract}
Liver transplant biopsies are routinely archived following formalin fixation and paraffin embedding and may provide an additional source of diagnostic information following transcriptomic biomarker analysis. This study was designed to compare gene transcription between resting and stressed biliary cells in culture, these cells after fixation and embedding and archival liver transplant biopsy tissue. The transcription of p21/WAF1 and transforming growth factor (TGF)- $\beta 1$ showed similar changes in the fresh and embedded liver cells. However, the expression of TGF- $\beta 2$ was markedly different between the fresh and embedded samples, suggesting that fixation can produce sequence-specific artefacts. Sufficient quantities of pure RNA were recovered from all the liver transplant biopsies to allow complementary DNA production. Measurement of the transcription of all three genes showed variability between the cases. Although the results for individual transcripts should be interpreted with care, these data do suggest the feasibility of performing a larger biomarker discovery studies using archival tissue.
\end{abstract}

\section{INTRODUCTION}

Liver transplant biopsy sections are routinely assessed with standard histological or immunohistochemical staining. ${ }^{1}$ However, there is a clear potential to recover improved diagnostic and prognostic information from allograft tissues by quantitative analysis of gene expression, ${ }^{2}$ which is unrealised. In order to minimise invasive liver biopsy procedures with their associated mortality and morbidity, it would be advantageous if the RNA for such research and analyses could be reliably isolated from the formalin-fixed, paraffin-embedded (FFPE) biopsy tissues used for histology.

Formalin fixation can modify nucleic acids by the addition of monomethylol groups to the bases. ${ }^{3}$ While this limits the recovery of full-length messenger RNA (mRNA), TaqMan chemistry allows gene transcription to be quantified by real-time PCR analysis of short complementary DNA (cDNA) sequences derived from fragmented mRNA. ${ }^{4}$ Another potential problem includes the unknown effects of oxidative degradation during block storage. This can be somewhat minimised by RNA isolation soon after fixation and by removing the most damaged superficial tissue. ${ }^{5}$

Despite these methodological advances, there has been no validation of systematic studies for the potential for gene expression analysis of FFPE human liver specimens. The current study was designed to examine the expression of a range of transplantation-relevant genes in resting and stressed biliary epithelial cells (BECs) before and after formalin fixation and paraffin embedding and to assess the applicability of these techniques for FFPE liver transplant biopsy samples.

\section{MATERIALS AND METHODS \\ Cells and stimulation}

The immortalised BEC line $\mathrm{H}_{6}{ }^{6}$ was cultured to confluence. Resting cells were compared against stressed cultures that had $200 \mu \mathrm{M} \mathrm{H}_{2} \mathrm{O}_{2}$ added to the medium for $2 \mathrm{~h}$; the cells were subsequently washed and returned to normal medium for 4,8 , 12, 24 and $36 \mathrm{~h}$. RNA was isolated from resting and stressed cells using TRI reagent (Sigma).

\section{Cell fixation and paraffin embedding}

Three cell pellets were created: resting cells, 12-hours post $-\mathrm{H}_{2} \mathrm{O}_{2}$ injury and 24 hours post- $\mathrm{H}_{2} \mathrm{O}_{2}$ injury. Cells were suspended in $10 \mathrm{~mL}$ of $10 \%$ neutral buffered formalin overnight at $4^{\circ} \mathrm{C}$. The cells were then centrifuged and the pellets embedded in paraffin.

\section{Tissue samples}

Six times zero (post-reperfusion) FFPE liver transplant biopsy specimens were used in this study. These tissue samples were from separate patients transplanted before 2006 in accordance with Research Ethics Committee approval (06/Q0905/150).

\section{FFPE mRNA isolation and validation}

RNA was isolated from FFPE liver tissue using an RNeasy FFPE kit (Qiagen). For each reaction, $4 \times 10 \mu \mathrm{m}$ sections were freshly cut from the FFPE blocks; the outer $40 \mu \mathrm{m}$ was discarded to minimise the effects of oxidation. The purity and quantity of each RNA sample was determined by Nanodrop spectrophotometry; RNA integrity was validated by agarose electrophoresis $(50 \mathrm{~mL}$ TAE buffer, $0.5 \mathrm{~g}$ agarose and $3 \mu \mathrm{L}$ Ethidium Bromide) and an AlphaImager (Alpha Innotech) to identify the $18 \mathrm{~S}$ and $28 \mathrm{~S}$ subunits of ribosomal RNA.

\section{CDNA synthesis and TaqMan real-time PCR}

The RNA was reverse transcribed to cDNA using an AffinityScript Multi-Temperature cDNA synthesis kit (Agilent Technologies). TaqMan chemistry was used with exon-spanning primers (Applied Biosystems) and a StepOne Plus real-time PCR system (Applied Biosystems) to quantify gene expression. The cycle threshold $\left(C_{t}\right)$ for genes of interest ( $\mathrm{p} 21 / \mathrm{WAF} 1$, transforming growth factor (TGF)- $\beta 1$ and TGF- $\beta 2$ ) was normalised using the 
housekeeping gene glyceraldehyde-3-phosphate dehydrogenase to allow calculation of fold changes in gene expression. ${ }^{7}$

\section{RESULTS}

Experiments in vitro showed that oxidative stress induced a significant increase in the expression of p21/WAF1, TGF- $\beta 1$ and TGF- $\beta 2$ by BEC (figure 1 ; all $\mathrm{p}<0.001$ ), with maximal upregulation observed after 12,12 and $4 \mathrm{~h}$, respectively. The RNA extracted from these cells before and after oxidative stress for 4 and $12 \mathrm{~h}$ (figure 2A) showed intact $18 \mathrm{~S}$ and $28 \mathrm{~S}$ ribosomal RNA subunits with no evidence of degradation. However, although the RNA-extracted FFPE cell pellets at these time points had a reasonable purity (typical A260/280 $=2.03$ indicating little protein contamination, and $\mathrm{A} 260 / 230=2.02$ indicating little solvent contamination), none of these samples showed discrete $18 \mathrm{~S}$ or $28 \mathrm{~S}$ bands (figure $2 \mathrm{~B}$ ). Gene expression analysis of these samples showed a significant increase in both p21/WAF1 and TGF- $\beta 112 \mathrm{~h}$ after oxidative stress (figure 3; both
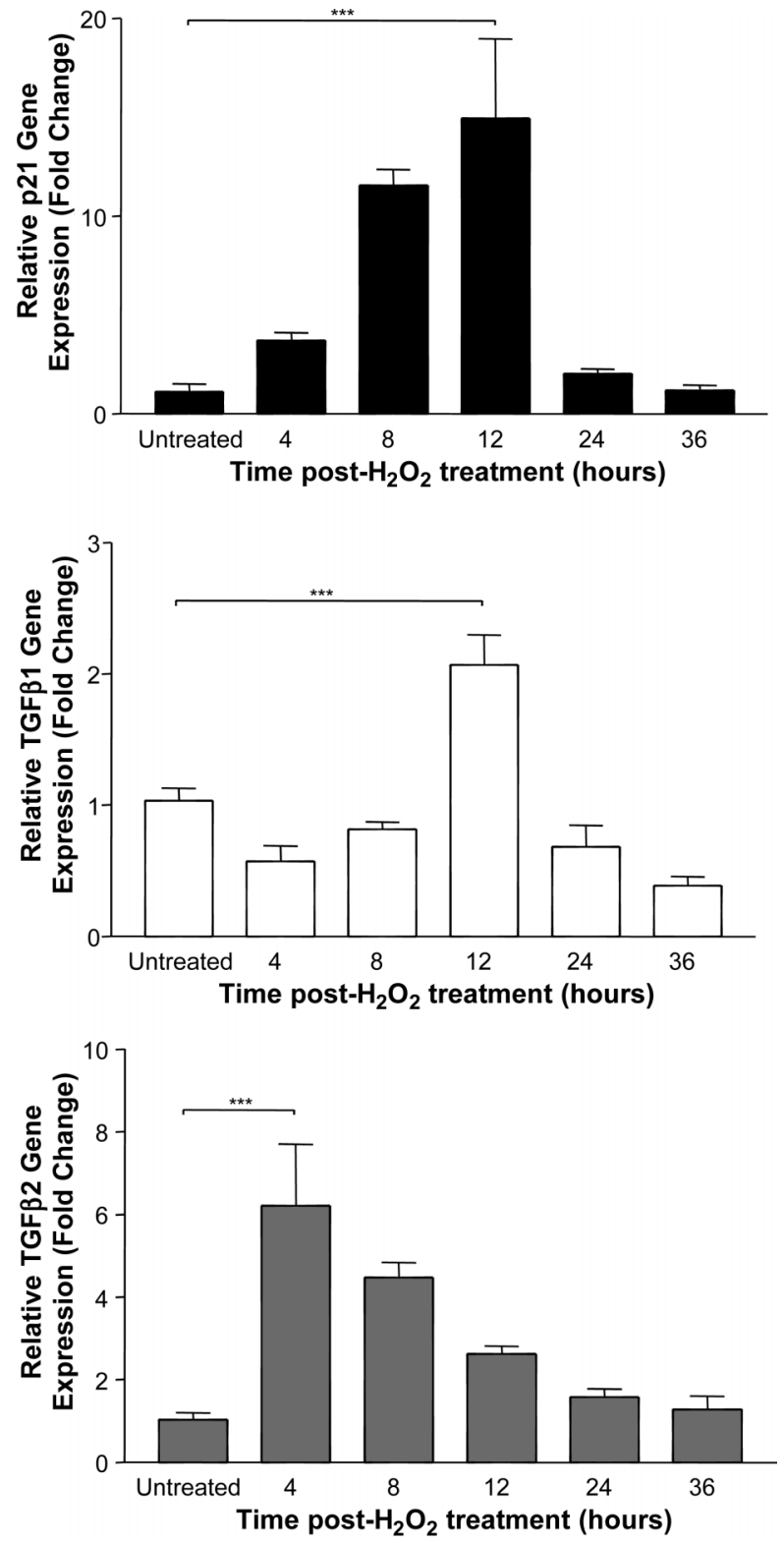

Figure 1 Measurement of gene expression by cultured human biliary epithelial cells at various times after $2 \mathrm{~h}$ of oxidative stress $\left({ }^{* *} p<0.001\right)$. Summary data of three separate experiments are shown.
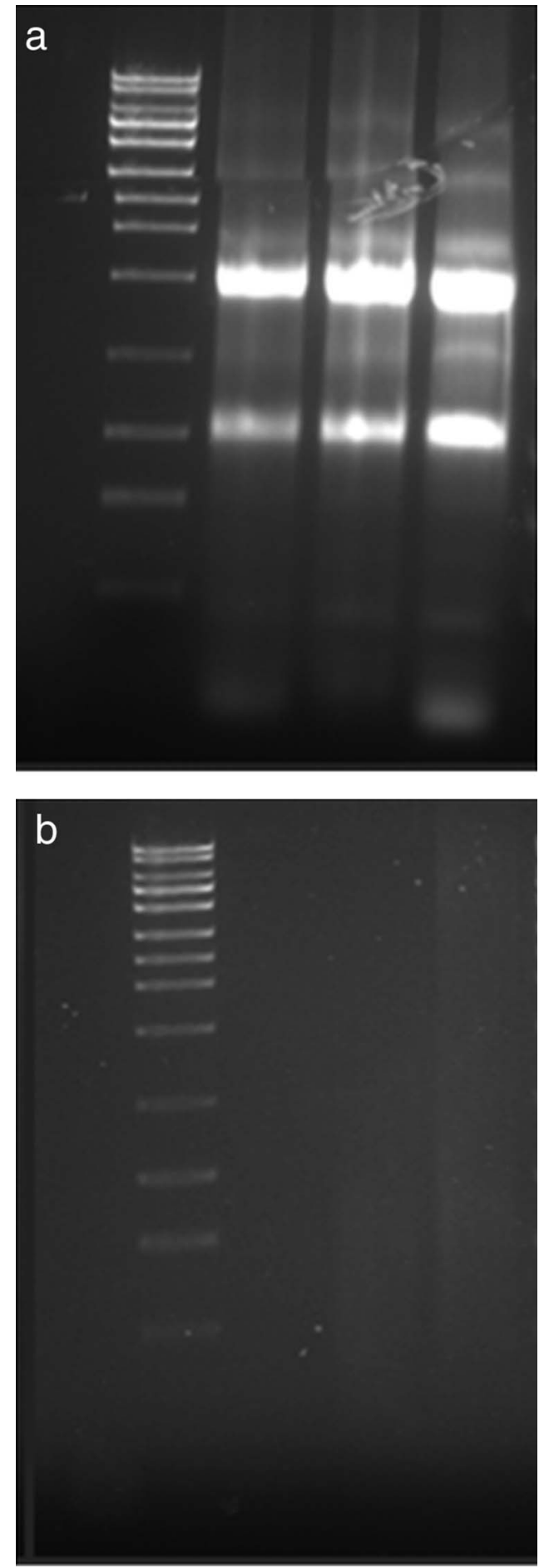

Figure 2 Representative gel showing RNA extracted from non-fixed (A) and formalin-fixed, paraffin-embedded processing (B) biliary epithelial cells; non-degraded $18 \mathrm{~S}$ and $28 \mathrm{~S}$ ribosomal RNA bands can be seen in panel $(A)$.

$\mathrm{p}<0.001)$. However, no expected increase was observed in expression of the TGF- $\beta 2$ transcript.

A quantity $(2.95 \pm 0.42 \mu \mathrm{g}$; mean \pm SEM) of pure RNA $(260 / 280$ and 260/230 ratios were all above 2) sufficient for cDNA production was isolated from sections of each of the six FFPE liver biopsy samples. After reverse transcription, each sample showed exponential amplification during real-time PCR generating measurable $C_{t}$ values. One of the six cases was arbitrarily chosen to normalise the summary data presented in figure 4. 

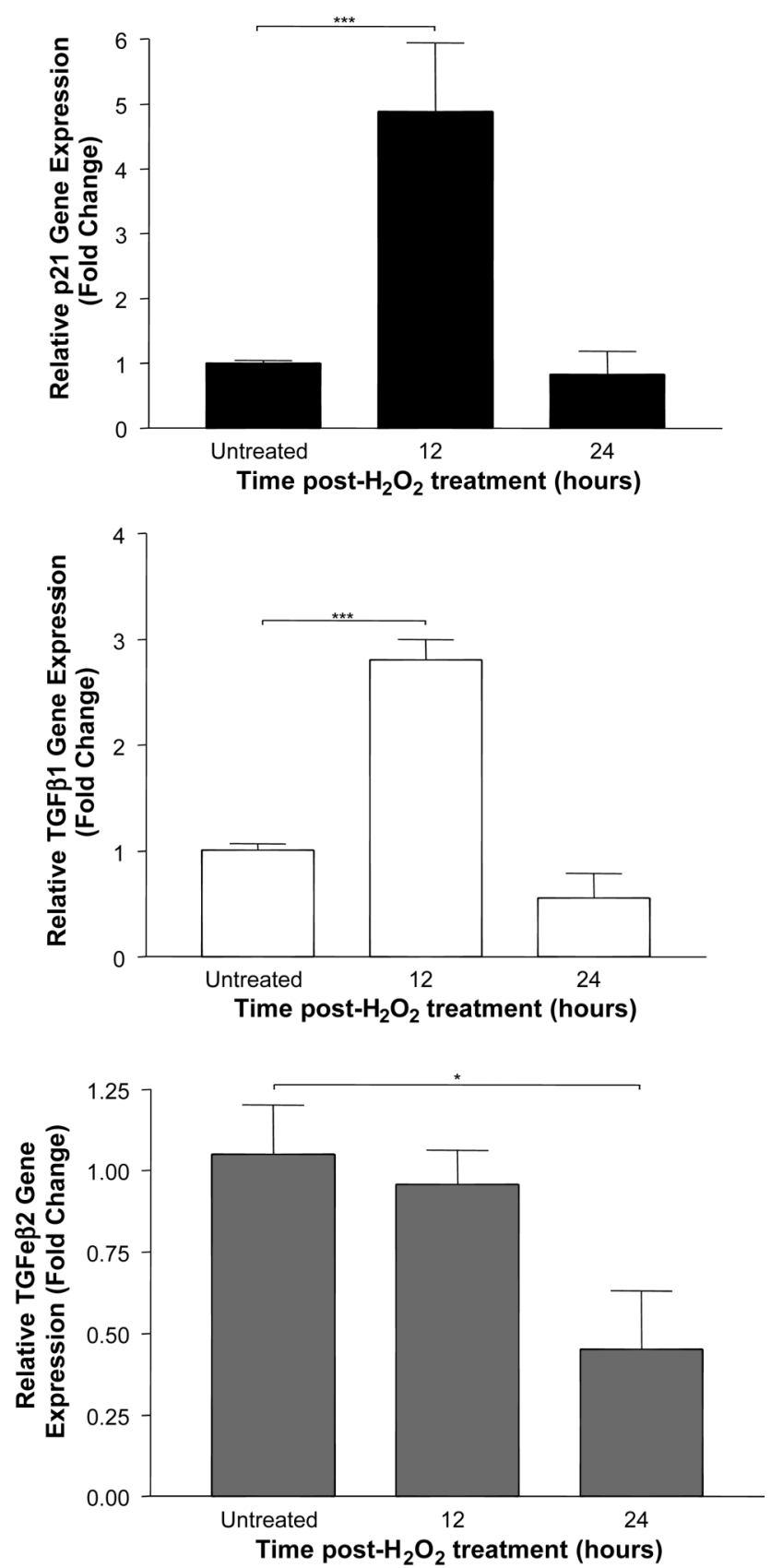

Figure 3 Measurement of gene expression by cultured human biliary epithelial cells at various times after a brief period of oxidative stress and following formalin-fixed, paraffin-embedded processing

$\left({ }^{* *} p<0.001\right)$. Summary data of three separate experiments are shown.

\section{DISCUSSION}

This study was designed to assess the feasibility of performing gene transcription analysis using archival FFPE liver biopsy material. Initial experiments defined the increase in expression of mRNA encoding the senescence marker $\mathrm{p} 21 / \mathrm{WAF} 1$ and the fibrogenic-immunoregulatory growth factors TGF- $\beta 1$ and TGF- $\beta 2$ by cultured human BEC following a brief period of oxidative stress. Results from this study were compared with similarly stressed cells after formalin fixation and embedding in paraffin.

Pure RNA could be extracted from the cultured cells after FFPE processing. However, the integrity of this RNA was certainly damaged and neither $18 \mathrm{~S}$ nor $28 \mathrm{~S}$ ribosomal RNA sequences could be identified. Real-time PCR analysis of cDNA

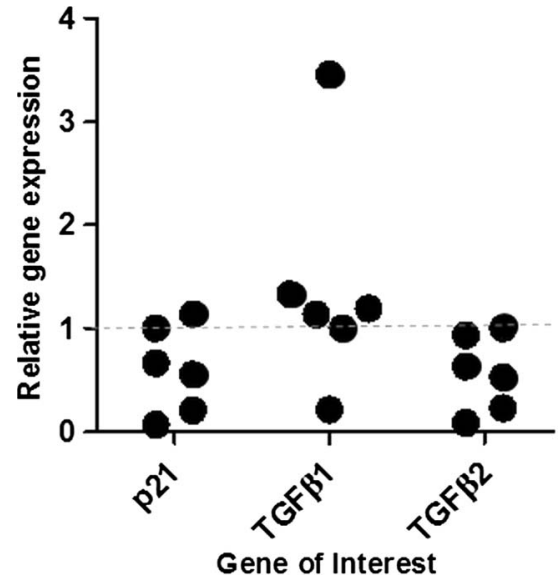

Figure 4 Gene expression analysis using formalin-fixed, paraffin-embedded biopsy-derived RNA from six liver transplant cases; all biopsy samples were taken at time zero immediately after reperfusion. All results were normalised to one arbitrarily chosen sample.

generated from this RNA demonstrated a similar stress-induced increase in p21/WAF1 and TGF- $\beta 1$ to that observed in fresh cells. Importantly, however, gene expression results for TGF- $\beta 2$ showed markedly different results between the fresh and FFPE cell pellets, with the latter cells indicating a decrease in expression of this gene. This result can be interpreted as providing evidence for sequence-specific damage produced by the FFPE process, suggesting that careful validation should always be performed before extending this analysis to RNA from biopsy material.

It was possible reliably to isolate sufficient quantities of pure RNA from sections cut from all six archival FFPE liver transplant biopsy blocks used in this study. After cDNA synthesis, the housekeeping gene and each of the three genes of interest could be detected during real-time PCR amplification. This study suggests the feasibility of performing a larger study incorporating biopsy material taken at later time points following liver transplantation. There have been previous studies looking into mRNA extraction from tumour tissue banks ${ }^{8}$ and in some types of liver disease with no attempt to investigate the effect of the FFPE process upon mRNA expression. The data from this study would indicate that such a study in liver samples should only be attempted after careful validation of individual mRNA stability by in vitro modelling.

\section{Key messages}

- mRNA of sufficient quality for analysis by real-time PCR can be recovered reproducibly from FFPE human liver tissue.

- Sequence specific mRNA degradation can occur during FFPE processing.

- There is evidence of heterogeneity in specific gene expression between different FFPE transplant liver specimens.

Contributors JGB, JAK, ADB, ET and CEB were involved in the conception and design, analysis and interpretation of data. JGB, ET, JAK and ADB were involved in the drafting the article or revising it critically for important intellectual content. JGB was responsible for the final approval of the version to be published. 
Funding This study was supported by the Wellcome Trust (Clinical Training Fellowship to JGB), The Newcastle NIHR Biomedical Research Centre and the MRC (PhD Studentship and Centenary Award to CB).

\section{Competing interests None.}

Provenance and peer review Not commissioned; externally peer reviewed.

Open Access This is an Open Access article distributed in accordance with the Creative Commons Attribution Non Commercial (CC BY-NC 3.0) license, which permits others to distribute, remix, adapt, build upon this work non-commercially, and license their derivative works on different terms, provided the original work is properly cited and the use is non-commercial. See: http://creativecommons.org/ licenses/by-nc/3.0/

\section{REFERENCES}

1 Demetris AJ, Eghtesad B, Marcos A, et al. Recurrent hepatitis C in liver allografts: prospective assessment of diagnostic accuracy, identification of pitfalls, and observations about pathogenesis. Am J Surg Pathol 2004;28:658-69.
2 Bustin SA. Real-time, fluorescence-based quantitative PCR: a snapshot of current procedures and preferences. Expert Rev Mol Diagn 2005;5:493-8.

3 Mizuno T, Nagamura H, Iwamoto KS, et al. RNA from decades-old archival tissue blocks for retrospective studies. Diagn Mol Pathol 1998;7:202-8.

4 Godfrey TE, Kim SH, Chavira M, et al. Quantitative mRNA expression analysis from formalin-fixed, paraffin-embedded tissues using $5^{\prime}$ nuclease quantitative reverse transcription-polymerase chain reaction. J Mol Diagn 2000;2:84-91.

5 von Ahlfen $\mathrm{S}$, Missel A, Bendrat $\mathrm{K}$, et al. Determinants of RNA quality from FFPE samples. PLoS One 2007;2:e1261.

6 Grubman SA, Perrone RD, Lee DW, et al. Regulation of intracellular pH by immortalized human intrahepatic biliary epithelial cell lines. Am J Physiol 1994;266(6 Pt 1):G1060-70.

7 Yuan JS, Reed A, Chen F, et al. Statistical analysis of real-time PCR data. BMC Bioinformatics 2006:7:85.

8 Hall JS, Leong HS, Armenoult LS, et al. Exon-array profiling unlocks clinically and biologically relevant gene signatures from formalin-fixed paraffin-embedded tumour samples. Br J Cancer 2011;104:971-81. 